\title{
KAJIAN DROMOLOGI DALAM IKLAN TVC OBAT SAKIT KEPALA BODREX - TERUS MENANGKAN HARIMU! TAHUN 2017
}

\author{
Alfian Candra Ayuswantana ${ }^{1}$, Diana Aqidatun Nisa ${ }^{2}$ dan Aileena Solicitor C.R.E.C ${ }^{3}$ \\ 1,2, 3 Program Studi Desain Komunikasi Visual, Fakultas Arsitektur dan Desain, \\ Universitas Pembangunan Nasional "Veteran" Jl. Rungkut Madya No.1, Surabaya, Jawa Timur 60294, Indonesia \\ alfianayuswantana.dkv@upnjatim.ac.id ${ }^{1}$,diananisa.dkv@upnjatim.ac.id ${ }^{2}$ aileena.dkv@upnjatim.ac.id ${ }^{3}$
}

\begin{abstract}
Abstrak: Kecepatan informasi membawa manusia dalam sebuah kondisi kesaling-terhubungan terus menerus antara seluruh jaringan komunikasi dan informasi. Kondisi banyaknya aliran arus informasi yang menerpa kita setiap saat seperti demikian dikenal sebagai schizophrenia baru. Keberadaan iklan tidak hanya menampilkan realitas yang merayakan kecepatan informasi dalam masyarakat mengagung-agungkan kecepatan, namun juga memegang peran penting dalam menularkan nilai-nilai ekstasi kecepatan (dromos) melalui nilai-nilai keseketikaan/instan yang dibawanya. Maka dari itu, fenomena pengagungan kecepatan dalam iklan menarik untuk ditelisik lebih dalam, yakni tentang cara-cara iklan tersebut dalam menyampaikan bujukan solusi keseketikaan yang ditawarkan kepada calon konsumennya. Melalui pendekatan beberapa teori seperti Dromologi, Simulasi dan Hiperealitas, serta teori Kuasa. Serial iklan TVC (Television Commercial) produk obat sakit kepala Bodrex sebagai Market Leader yang disiarkan pada rentang tahun 2017 dipilih menjadi studi kasus dalam membedah nilai-nilai dromologi pada iklan tersebut. Dari hasil analisis ditemukan cara-cara rayuan kepada konsumen yang dipilih melalui pendekatan dromologi berdasarkan konsep solusi instan/ kesegeraan.
\end{abstract}

Kata kunci: Dromologi, Iklan bodrex, Hiperealitas, Hegemoni

\begin{abstract}
The speed of information access brings people into one condition of continuous interconnection between all communication and information networks. The condition of information bombardment that hits us every time is known as the new schizophrenia. The existence of advertising not only displays the reality that celebrates the rapid velocity of information in a society that glorifying speed, but advertising also plays an important role in transmitting the values of ecstasy velocity (dromos) through the instantaneous values it carries. The phenomenon of the glorification of speed in ads is interesting to be investigated more deeply, about the ways these advertisements conveyed the persuasion of instantaneous solutions offered to prospective customers. Through the approach of several theories such as Dromology, Simulation and Hypereality, and the theory of Power. TVC (Television Commercial) advertising series Bodrex headache drug product as a market leader that aired in the range of 2017 was chosen as a case study in dissecting the dromological values of the advertisement.
\end{abstract}


From the analysis of these advertisements, it ws found ways of seduction to consumers chosen through the dromology approach as seen from the concept of instant solutions.

Keywords: Dromology, Bodrex Advertising, Hypereality, Hegemony

\section{PENDAHULUAN}

Fenomena dromologi dalam iklan menarik untuk diteliti, bagaimana cara-cara iklan tersebut dalam menyampaikan bujukan solusi keseketikaan yang telah jamak ditawarkan kepada calon konsumennya. Menurut Williamson (2007), Kita hanya dapat memahami pesan-pesan pada iklan dengan memahami bagaimana iklan tersebut bekerja. Fenomena dari tren solusi keseketikaan mudah dan kental terasa terutama pada jenis iklan produk obat-obatan. Umumnya iklan obat terdapat 2 pesan utama yang ingin disampaikan, iklan-iklan yang menawarkan keefektifan menghilangkan gejala dan disamping itu selain menawarkan keefektifan juga menawarkan keseketikaan dalam menyembuhkan. Fenomena tren keseketikaan dalam iklan, sangat erat berkelindan dengan kondisi sosio-kultural masyarakat saat ini. Eksistensi iklan komersial tidak mungkin lepas dari karakteristik serta kebutuhan konsumen, Moriarty (dalam Yani dan Nisa, 2018) mengemukakan beberapa unsur penting dalam merencanakan pesan, yaitu consumer insight dan promise sesuai dengan pendapat E.B. White seorang penulis Amerika (dalam Danesi, 2002), Iklan mengejawantahkan impian kita, senjata utama iklan adalah kelemahan-kelemahan kita: ketakutan kita, ambisi kita, kebanggaan kita, keinginan kita, ketidak-pedulian kita dan lain sebagainya. Serial iklan TVC (Television Commercial) Bodrex yang diterbitkan pada rentang tahun 2017 dipilih menjadi studi kasus dalam membedah nilai-nilai dromologi pada iklan.

Iklan Bodrex dinilai tepat untuk menjadi contoh kasus karena Bodrex sebagai produk obat terkemuka yang dijual bebas tanpa resep dokter, merek dagang Bodrex telah ada selama 40 tahun, juga merupakan top brand di Indonesia dan beberapa kali $\begin{array}{lllll}\text { mendapatkan } & \text { Top } & \text { Brand } & \text { Award }\end{array}$ (http://www.bodrex.com/gallery/photo). Iklan TVC Bodrex menjadi unik dikarenakan 
Bodrex mengklaim dirinya sebagai solusi terbaik dan tercepat untuk mengatasi sakit kepala dengan pendekatan gaya hidup konsumennya.

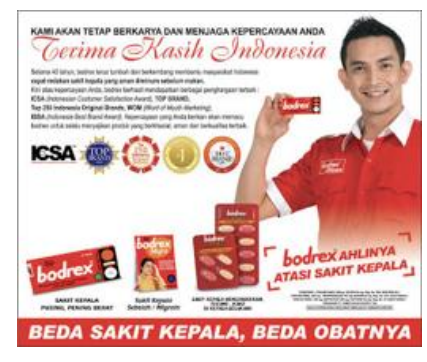

Gambar 1. Sederet prestasi Bodrex dalam dunia kesehatan. (Sumber: http://3.bp.blogspot.com/BdrErDTOt8w/UfdesB07fPI/AAAAAAAABFo/j2f1wRHU7JU/s1600/Bodrex3.jpg, akses 25 April 2017).

Paul Virilio dalam bukunya yang berjudul Speed and Politics, mengemukakan bahwa diam berarti kematian, sebuah hukum alam semesta (Virilio, 2007, p. 89). Kecepatan merupakan ciri sebuah kemajuan, yang akan menghasilkan kemajuankemajuan lainnya dalam tempo yang tinggi (Piliang, 2004, p. 83). Menurut Virilio manusia mengalami revolusi dalam memaknai kecepatan dimulai dengan momentum peristiwa revolusi industri, Virilio berpandangan bahwa peristiwa revolusi industri merupakan bukan hanya terjadi sebuah revolusi besar-besaran terhadap inovasi mesin-mesin industri melainkan juga terjadi sebuah revolusi sosial masyarakat terhadap konsep 'kecepatan' menjadi masyarakat apa yang dinamakan Virilio sebagai dromokrasi (Virilio, 2007, p. 46). Dromokrasi yaitu sebuah struktur masyarakat dimana kecepatan menjadi kekuasaan tetinggi.

Seiring dengan kemajuan teknologi, arus kecepatan tidak hanya dimaknai dengan efisiensi dan efektifitas perpindahan gerak namun juga mengakibatkan percepatan arus informasi antar manusia. Kecepatan arus informasi membawa manusia dalam sebuah kondisi kesaling-terhubungan terus menerus antara seluruh jaringan komunikasi dan informasi. Kondisi yang demikian diistilahkan oleh Baudrillard dengan istilah schizophrenia baru (Baudrillard, 2015, p. 17). Hal ini dapat dilihat bagaimana arus informasi bergerak antar manusia, sebelum ditemukannya telepon 
manusia mengandalkan komunikasi jarak jauh dengan surat-menyurat dalam hitungan hari bahkan bulan, namun keberadaan teknologi terus memacu percepatan arus informasi tersebut sehingga dapat secepat mungkin dan secepat mungkin, hingga munculnya fenomena telepon genggam nirkabel yang mampu memutus rentang waktu tersebut menjadi seketika. Contoh tersebut menjadi cerminan bagaimana manusia hidup dalam kecepatan.

Kondisi yang demikian menjadi sangat kompleks ketika arus informasi yang diarahkan kepada kita tidak hanya berjumlah satu atau beberapa saja namun ratusan bahkan ribuan informasi ditujukan kepada kita setiap saat, setiap waktu ketika kita bersentuhan dengan dunia. Kita tidak ubahnya menjadi seperti layar tempat segala informasi diproyeksikan sesuai dengan pandangan Baudrillard (Baudrillard, 2015), laksana sebuah layar kosong, berbagai macam informasi pesan dari iklan diproyeksikan secara semena-mena kepada setiap ruang yang kita miliki. Menurutnya (dalam Piliang, 2003) kita adalah massa, mayoritas yang diam, kita menyerap segala apa yang diproyeksikan kepada kita, tanpa mampu merefleksikannya. Iklan merupakan salah satu contoh yang tepat bagaimana kecepatan arus informasi diproyeksikan kepada kita.
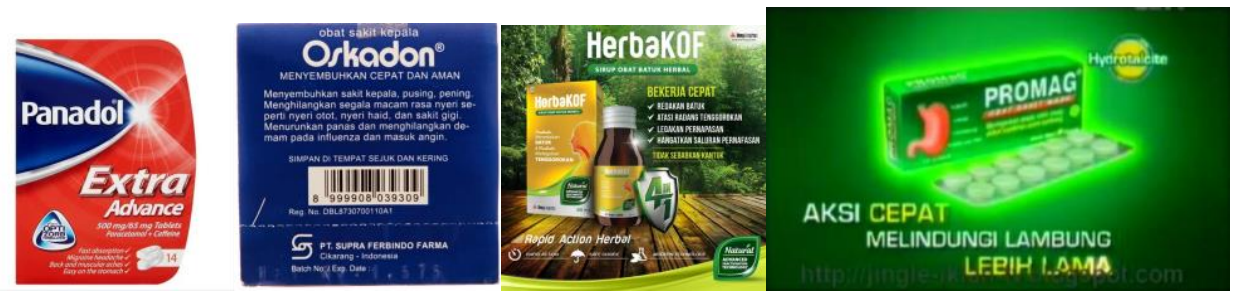

Gambar 2. Beberapa Iklan obat yang menawarkan keseketikaan (instant). (Sumber : https://s4.bukalapak.com/img/4384648673/w-

1000/5970949_78044b8c_29a6_4a56_8701_5e8885e5c702_500_500.jpg,

https://cf.shopee.co.id/file/aeba85d08499e3f3c546b469af44af72,

https://awsimages.detik.net.id/community/media/visual/2016/02/08/52f3cf9f-4915-40e6-9abof4c0436d7547.jpg?w=700\&q=90, https://docplayer.info/docs-images/69/61198307/images/47-0.jpg, akses 18 maret 2020). 


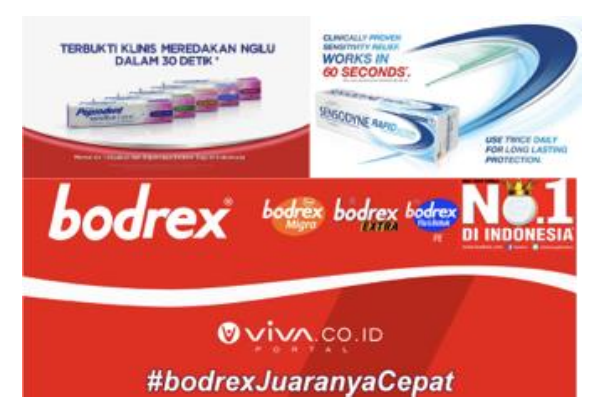

Gambar 3. Pesan-pesan keseketikaan dalam kesehatan. (Sumber:

http://www.24onlinebazar.com/image/catalog/HEALTH_PERSONAL_CARE/HEALTH/OTC_Medi/Tooth_P aste_Wash/Sensodyne_Rapid_Relief_Toothpaste_24OnlineBazar.jpg, http://3.bp.blogspot.com/TUROV76Zmkk/VQCSDgPrCsI/AAAAAAAACFO/CgS7dGyLecA/s1600/maxresdefault.jpg, http://1.bp.blogspot.com/-ssLOveXdbrO/UfW8vga7B9I/AAAAAAAAAWw/NkVw8nSJVQ/s1600/Bodrex+Juaranya+Cepat.jpg, akses 25 April 2017).

Keberadaan iklan dimanapun berada, mereka menjelajahi dunia kita melalui televisi, radio, billboard, di bus kota, di angkot, di koran-koran dan majalah, di poster dinding, di mural bangunan, pada baju, pada sepatu pada pasta gigi, pada botol minuman, ponsel dan lain sebagainya. Kotler dan Keller dalam Adelia et al., (2018), mengidentifikasikan iklan sebagai segala bentuk yang berbayar dari presentasi non personal dan promosi dalam bentuk ide, barang, ataupun jasa dari sponsor yang telah ditentukan. Pesan-pesan iklan disampaikan melalui teknik non-verbal maupun verbal yang dibungkus rapi dalam kemasan persuasif yang menggoda. Menurut Danesi (2002), dengan iklan menyampaikan konstan terus menerus dengan berbagai media hal ini dilakukan dalam rangka mendominasi informasi pesan di kehidupan kitadapat seolah-olah menciptakan ilusi produk yang ditampilkannya berpengaruh dan berkaitan langsung dengan kondisi sosial dan tren dimasyarakat, dengan kata lain perilaku iklan yang demikian dirancang agar iklan mampu mengontrol pola konsumsi kita melalui tren yang diciptakannya. Keberadaan iklan turut memacu terciptanya sebuah kondisi seperti yang dikemukakan Baudrillard (2015), yaitu kondisi sistem kebutuhan adalah produk dari sistem produksi. Sebuah kondisi dimana kebutuhan tidak lagi ada karena kondisi manusia yang memerlukan sesuatu untuk dipenuhi melainkan kebutuhan tercipta karena manipulasi keinginan-keinginan yang berangkat 
dari munculnya produk-produk baru yang sudah tidak relevan lagi dengan fungsi awalnya.

Keberadaan iklan tidak hanya menampilkan realitas yang merayakan kecepatan informasi dalam masyarakat dromokrasi, namun iklan juga memegang peran penting dalam menularkan nilai-nilai ekstasi kecepatan melalui nilai-nilai keseketikaan/instan yang dibawanya. Dapat dengan mudah kita jumpai di media-media periklanan disekitar kita tentang strategi iklan mengkomunikasikan produk-produknya dengan bujukanbujukan yang berisi nilai-nilai keseketikaan. Bujukan-bujukan nilai keseketikaan tersebut dapat berwujud dengan menampilkan informasi kecepatan produk seperti contoh diatas bagaimana iklan So-klin dan Nescafe menawarkan kemampatan ketika berproses dengan produk tersebut, dengan menampilkan nilai-nilai 'lebih' dan menggabungkan beberapa hal dalam satu produk. Selain menawarkan nilai-nilai kemampatan dalam sebuah produk diatas, tidak jarang pula kita melihat bagaimana beberapa iklan menawarkan solusi keseketikaan dalam produknya, ketika kita mengkonsumsi produk tersebut masalah yang kita sedang alami menjadi hilang seketika seperti iklan Pepsodent Sensitive Expert, Sensodyne Rapid Relief, dan iklan obat sakit kepala Bodrex yang kesemuanya itu menawarkan solusi instan atas masalah gigi sensitif atau sakit kepala yang dirasakan konsumen.

Terdapat beberapa pendekatan teori untuk membedah pesan-pesan dromologi dalam iklan TVC Bodrex antara lain; Teori dromologi, teori iklan, teori cara kerja iklan, teori gaya hidup dan teori kekuasaan. Teori dromologi dikemukakan oleh Paul Virilio, di dalam teori ini mengulas bagaimana fenomena ini terjadi di masyarakat saat ini. Dalam bukunya Speed and Politics, Virilio menjelaskan lebih lanjut tentang bagaimana manusia mengalami revolusi pemikiran terhadap pemaknaan kecepatan. Virilio mengistilahkan keilmuan tersebut dengan istilah Dromologi, yang berasal dari bahasa latin Dromos yang berarti berlari kencang dan Logos yang berarti ilmu. Virilio menuturkan dromologi membawa instrumen-instrumen yang mengikutinya antara lain 
Dromocracy yang bermakna masyarakat yang menjunjung tinggi nilai-nilai kecepatan dan Dromotariat yaitu individu-individu yang menganut, meyakini dan melaksanakan nilai-nilai tersebut.

Teori simulasi dan hiperealitas Baudrillard, adalah teori yang banyak membahas tentang bagaimana cara kerja sebuah iklan dalam membangun efek hiperreal, dalam rangka membujuk konsumennya. Sebuah iklan yang merupakan rangkaian kodifikasi pesan untuk membujuk konsumen. Iklan sebagai sebuah bentuk dari kebudayaan massa, menurut Tinarbuko (2009) iklan bertujuan menawarkan dan mempengaruhi calon konsumen untuk membeli barang/jasa, iklan juga dalam penyampaian pesannya membawa nilai-nilai tertentu yang terpendam di dalamnya.

Kodifikasi merupakan strategi atau cara mengolah kode-kode dalam menyampaikan pesan, menggunakan kombinasi tanda-tanda (Piliang dalam Tinarbuko, 2009). Tanda-tanda tersebut dibentuk oleh kesatuan penanda-penanda dan petandapetanda (Saussure dalam Barthes, 2017), maka untuk memetakan bagaimana pemetaan pesan yang disampaikan dapat dilihat dari intensitas penanda-penanda yang ditampilkan dalam sebuah iklan.

Teori kekuasaan Bourdeu dapat ditarik untuk mengulas bagaimana sebuah iklan mampu mempengaruhi dan membujuk konsumennya untuk membeli produk tersebut. Dalam teori ini iklan merupakan sebuah alat untuk berlomba-lomba menghegemoni informasi yang diproyeksikan kepada konsumen, dalam rangka hegemoni tersebut, iklan menggunakan cara-cara halus untuk membuat proses hegemoni nilai-nilai yang disampaikan tersebut dapat diterima dengan tidak terasa. Keinginan untuk membeli produk (minat beli) sesuai Ferdinand (dalam Foster et al., 2019), minat beli dapat dikenali melalui petunjuk sebagai berikut: intrik transaksional, intrik referensial, minat preferensial, dan minat eksploratif. 


\section{METODE PENELITIAN}

Proses penggalian sumber data primer melalui iklan Bodrex yang tersaji dalam situs Youtube, yang disandingkan dengan berbagai sumber literatur terkait. Penelitan ini bersandar pada pendekatan sosiologis. Metode kualitatif analisis wacana kritis digunakan sebagai upaya untuk menjawab tujuan penelitian diatas. Fairclough dalam Sumartono (2017, p. 176), mengemukakan analisis wacana kritis memiliki beberapa dimensi wacana. Pada penelitian ini dimensi pertama melalui analisis objek yang menggunakan analisis teks. Dalam dimensi pertama ini diawali pembedahan elemen visual tanda melalui metode Feldman (dalam Anderson, 1986, p. 54) yang memetakan elemen-elemen visual tanda dalam iklan, yang kemudian dijelaskan relasi formal masing-masing tanda-tanda visual tersebut, sedangkan relasi makna menggunakan semiotika model Barthes. Dimensi kedua aspek konteks yang menggunakan analisis interpretasi, dan dimensi ketiga kuasa dalam wacana yang menggunakan analisis sosial/eksplanasi yang bersandar pada sudut pandang Dromologi dari Virillio, yang ditunjang oleh teori Kuasa dari Beordieu serta teori hiperealitas dari Baudrillard.

\section{HASIL DAN DISKUSI}

\section{a. Dimensi Pertama - Analisis teks.}

Komunikasi dalam Iklan senantiasa menggunakan dibangun menggunakan rangkaian tanda yang terkodefikasikan. Tanda menurut Barthes di dalamnya terdiri atas Penanda dan Petanda. Petanda atau makna terdiri dari makna detonasi adalah makna sebenarnya dari sebuah benda atau objek sesuai dengan makna sebenarnya, sedangkan konotasi kebalikannya adalah makna yang tidak sebenarnya atau makna ganda yang muncul dari pengalaman personal atau kultural (Barthes dalam Nurusholih, 2019). 
Alfian Candra Ayuswantana, Diana Aqidatun Nisa dan Aileena Solicitor C.R.E.C KAJIAN DROMOLOGI DALAM IKLAN TVC OBAT SAKIT KEPALA BODREX - TERUS MENANGKAN HARIMU! TAHUN 2017,

Tabel 1. Iklan Bodrex I: Bodrex Migra Terus Menangkan Harimu!-Acha Septriasa (2017) Sumber: https://www.youtube.com/watch?v=TXe8wSAjznE

\begin{tabular}{llll}
\hline Potongan Gambar TVC & Narasi Verbal & Narasi Aksi & Durasi \\
& Suasana & - & $0: 01$ \\
aktivitas & $0: 06$ \\
& sekelompok & \\
& rekreasi & \\
dengan suka & \\
& cita. & \\
& &
\end{tabular}

$\begin{array}{lll}\text { Loh kepala kamu } & \text { Tiba-tiba } & 0: 07 \\ \text { kenapa? } & \text { salah satu } & \text { 0:10 } \\ & \text { anggota } & \\ & \text { kelompok } & \\ & \text { mengalami } \\ & \text { sakit kepala. }\end{array}$

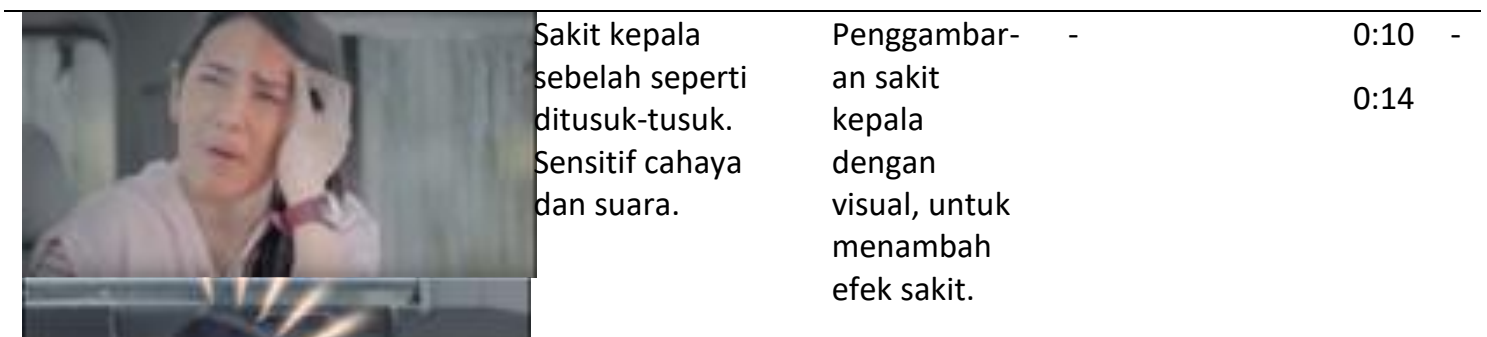
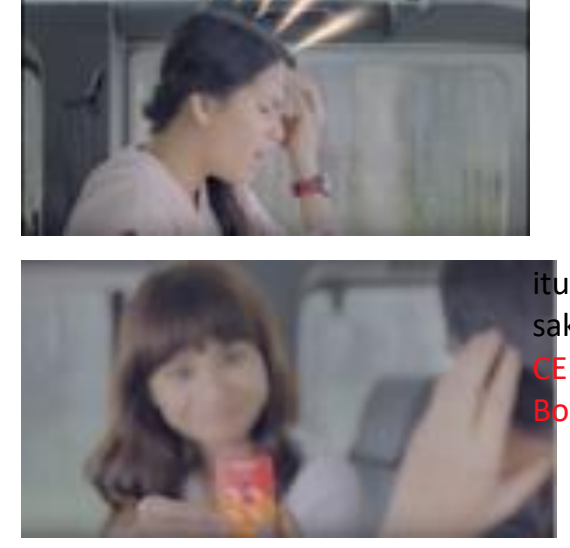

u migrain! Bukan kit kepala biasa, PAT minum

Salah satu teman, yang Bodrex.

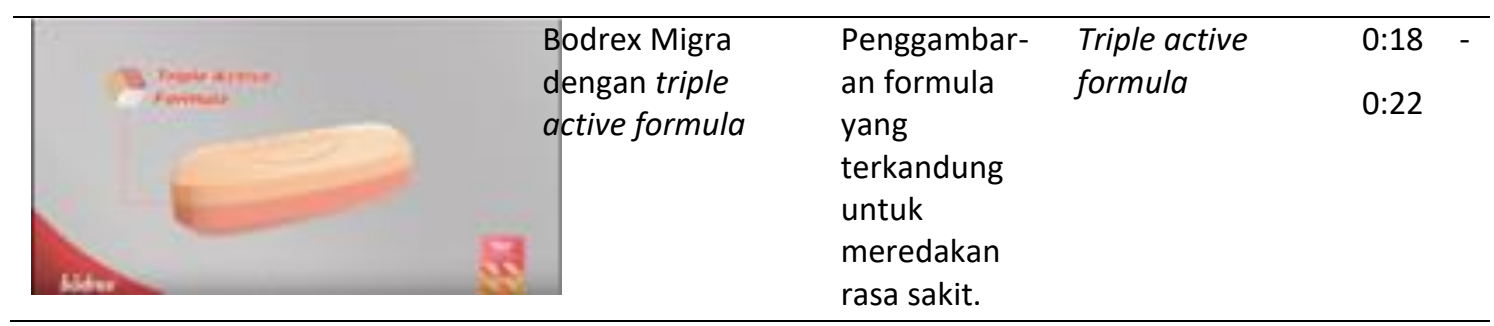




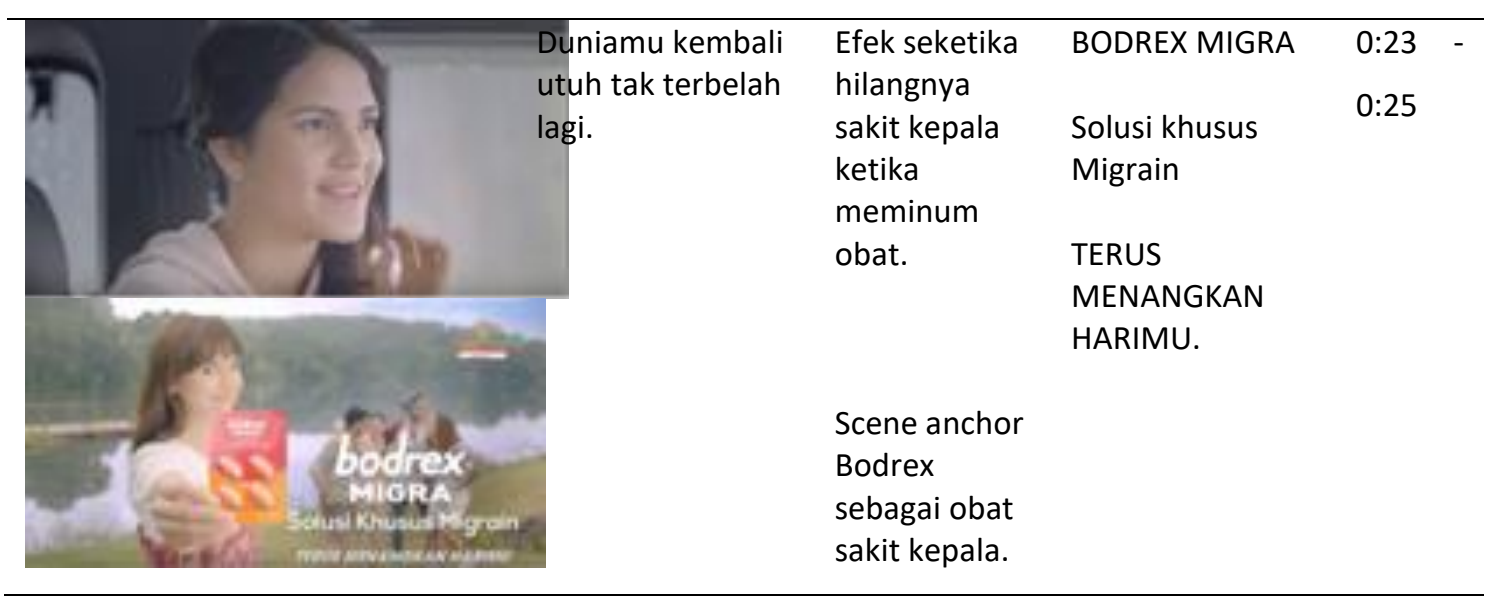

Tabel 2. Iklan Bodrex II: Terus Menangkan Harimu! - Dion Wiyoko (2017) Sumber: https://www.youtube.com/watch?v=QgXrH0GOT28

\begin{tabular}{|c|c|c|c|c|c|}
\hline Potongan Gambar TVC & Narasi Verbal & Narasi Aksi & Narasi Teks & Duras & \\
\hline & $\begin{array}{l}5 \text { menit lagi } \\
\text { lomba akan } \\
\text { segera dimulai. }\end{array}$ & $\begin{array}{l}\text { Suasana } \\
\text { aktivitas } \\
\text { sekelompok } \\
\text { rekreasi } \\
\text { dengan suka } \\
\text { cita. }\end{array}$ & - & $\begin{array}{l}0: 02 \\
0: 06\end{array}$ & - \\
\hline & $\begin{array}{l}\text { A : Aduh kenapa } \\
\text { udah mau mulai } \\
\text { nih! } \\
\text { B : Sakit kepala. }\end{array}$ & $\begin{array}{l}\text { Tiba-tiba } \\
\text { salah satu } \\
\text { anggota } \\
\text { kelompok } \\
\text { mengalami } \\
\text { sakit kepala. }\end{array}$ & - & $\begin{array}{l}0: 06 \\
0: 09\end{array}$ & - \\
\hline & & $\begin{array}{l}\text { Penggambara } \\
\text { n sakit kepala } \\
\text { dengan } \\
\text { visual, untuk } \\
\text { menambah } \\
\text { efek sakit. }\end{array}$ & - & $\begin{array}{l}0: 10 \\
0: 12\end{array}$ & - \\
\hline $3=$ & $\begin{array}{l}\text { CEPAT minum } \\
\text { Bodrex! jangan } \\
\text { sampai } \\
\text { ketinggalan } \\
\text { aksimu }\end{array}$ & $\begin{array}{l}\text { Salah satu } \\
\text { teman, yang } \\
\text { diperankan } \\
\text { oleh artis film } \\
\text { menawarkan } \\
\text { Bodrex. }\end{array}$ & $\begin{array}{l}\text { Dapat diminum } \\
\text { sebelum makan. }\end{array}$ & $\begin{array}{l}0: 13 \\
0: 15\end{array}$ & - \\
\hline
\end{tabular}




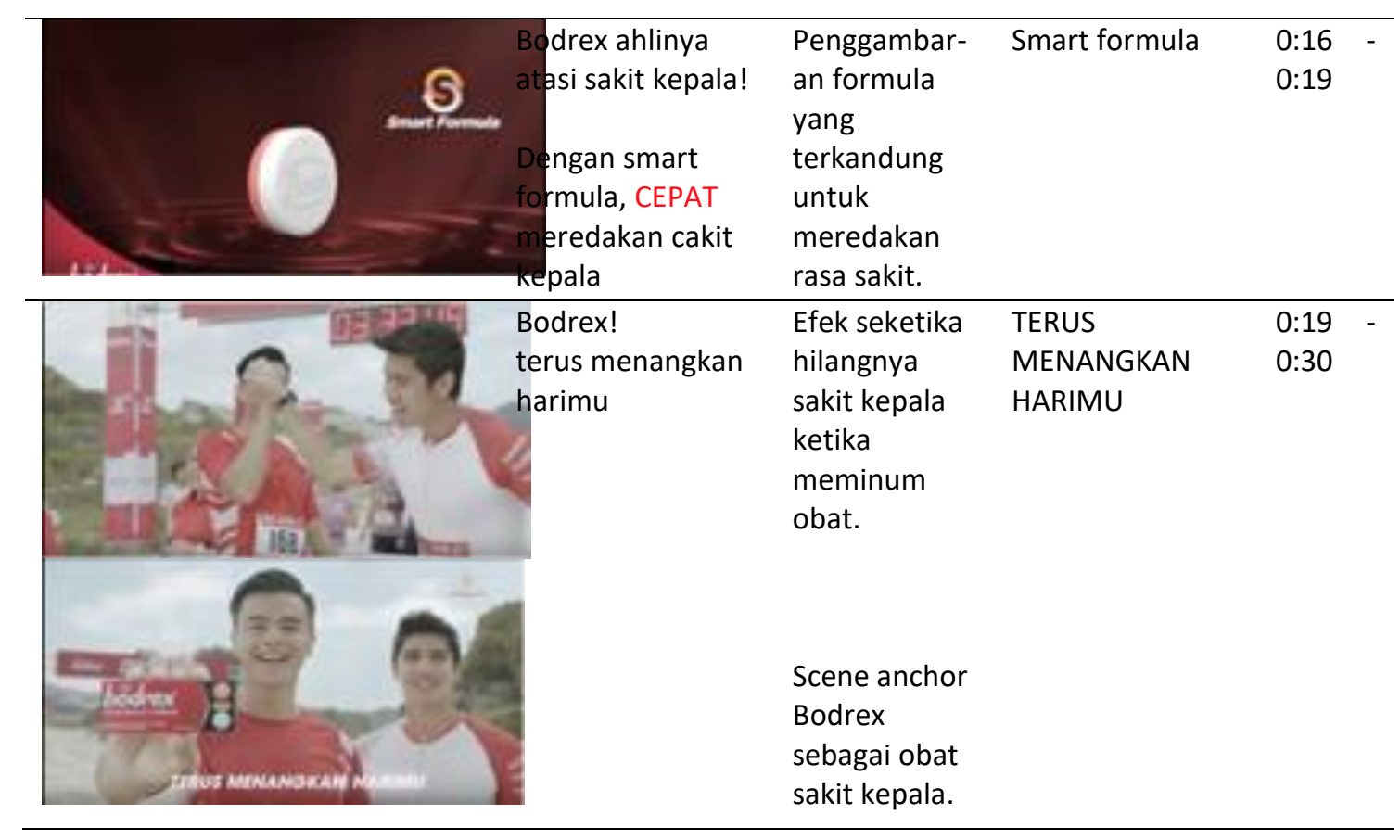

Dalam dua iklan Bodrex di atas nampak memiliki beberapa kesamaan pola penyampaian pesan antar keduanya. Proses penyampaian pesan keduanya, iklan mengawali dirinya dengan penggambaran kondisi aktor-aktor iklan menjalankan aktivitasnya dengan penuh kegembiraan dan semangat, namun ditengah aktivitas tersebut salah seorang di antara pemeran tersebut mengalami serangan sakit kepala. Iklan bodrex ini menggambarkan visualisasi sakit kepala seolah-olah terasa sangat menyakitkan, melihat hal tersebut aktor utama (Acha Septriasa dan Dion Wiyoko) mengucapkan "...cepat minum Bodrex!". Bodrex menampilkan penggambaran kekuatan Bodrex sebagai obat yang ampuh sebagai solusi sakit kepala dengan menghadirkan penjelasan formula 'ajaib' yang ada dalam dirinya. Ketika seorang yang sedang mengalami gangguan sakit kepala tersebut meminum Bodrex, seketika sakit kepala hilang dan senyum pun merekah di wajah aktor tersebut, yang kemudian melanjutkan aktivitasnya kembali. Akhir iklan Bodrex, menampilkan sosok merek Bodrex beserta tagline yang nampak yaitu 'Bodrex, terus menangkan harimu'. 


\section{b. Dimensi Kedua - Analisis teks.}

Rangkaian iklan Bodrex di atas merupakan bagian dari upaya manajemen Tempo Scan sebagai perusahaan induk produk Bodrex dalam meremajakan produk Bodrex yang pada tahun 2015 telah berumur 45 tahun. Bodrex sebagai Market Leader obat sakit kepala, ingin memperluas target pasarnya pada segmen anak muda. Mendukung kebijakan tersebut, pada Desember 2015 manajemen Bodrex meluncurkan kampanye bertemakan "Menangkan Harimu". Tema ini juga menjadi topik utama dalam iklan TVC diatas dengan slogan \#MenangkanHarimu. Dikutip dari Mix.Co.Id (Wulandari, 2016) 5 Januari 2016, dengan adanya \#MenangkanHarimu, Bodrex dapat mendampingi masyarakat generasi muda agar tetap semangat dan pantang menyerah di setiap harinya dalam rangka mencapai impian.

Dari penjelasan diatas dapat diartikan bahwa bodrex ingin menjadi Product Generator dari semangat-semangat keanak-mudaan yang pantang menyerah. Caracara Bodrex dalam melanggengkan tema tersebut pada anak muda adalah dengan menyelipkan karakter anak muda millenial yang serba instan dan penuh kesegeraan, dengan kata lain wacana dromologi menjadi ordinat dalam setiap pesan iklan Bodrex 2017.

\section{c. Dimensi Ketiga - Analisis Sosial.}

Iklan Bodrex menyampaikan pesannya dengan merekonstruksi dan mensimulasikan keadaan yang kemungkinan terjadi dalam kehidupan konsumennya. Bodrex membangun imaji dirinya menjadi solusi yang tepat dan cepat saat kondisi sakit kepala tiba-tiba datang. Simulasi ini dihadirkan dengan tujuan untuk membentuk efek hiperealitas yang seolah-olah nampak sebagai kenyataan yang terjadi di masyarakat. Media iklan berupa video atau televisi sangat cocok untuk menjamin bekerjanya sistem tersebut, menurut Thwaites dkk (2011, p. 224) mengemukakan bahwa efek kehadiran imaji visual nampak lebih nyata dalam televisi. Imaji yang disampaikan lewat 
televisi menawarkan sebuah gambaran yang lebih langsung, akurat dan intim. gambaran yang disampaikan televisi nampak seolah-olah benar-benar terjadi.

Setiap iklan dalam melakukan sebuah bujukan senantiasa membutuhkan suatu instrumen di dalamnya untuk penyampaikan konsep pesan bujukannya. Menurut Piliang (2003) instrumen di dalam iklan tersebut berupa tanda-tanda yang jika dibuka lebih dalam terdiri atas rangkaian penanda-penanda - yang dapat dalam wujud gambar, foto, maupun illustrasi - dan petanda atau makna yang memaknai petandapetanda tersebut, penanda dan petanda tersebut digunakan untuk melukiskan realitas tertentu maupun untuk membangun sebuah realitas palsu. Iklan dalam hubungannya dengan dunia nyata, iklan dapat menjadi sebuah Mirror of Reality yang mencerminkan realitas nyata yang ada maupun menjadi Distorted Mirror or Reality mencerminkan realitas rekaan/palsu yang tidak pernah memiliki referensi di dunia nyata. Kepalsuan realitas pada pesan iklan tersebut dibuat dalam rangka mengendalikan pola konsumsi kita. Senada yang dikemukakan oleh Baudrillard (2006), bahwa periklanan dapat dikatakan mengagungkan semua objek, dengan cara penyaringan/sensor dan cara mengartikulasikan objek iklan, serta memaksakan sistem penalaran tertentu menetralkan pesan sesungguhnya produk iklan dan menggantikannya dengan makna manipulasi baru ke dalam produk tersebut. Menurut Baudrillard (2015, p. 152), semakin dalam penyempurnaan teknik, realitas dunia semakin hilang. Dalam pengertian ini bahwa jika sebuah objek atau peristiwa ditampilkan media semakin sempurna mendekati wujud aslinya maka realitas sesungguhnya akan semakin menghilang dan tergantikan oleh realitas buatan yang disampaikan oleh televisi.

Piliang (2003) menambahkan bahwa melalui model-model simulasi dapat dihasilkan sebuah kondisi di mana manusia terjebak di dalam sebuah ruang yang disadarinya sebagai kenyataan walaupun pada dasarnya realitas tersebut merupakan realitas semu atau khayalan belaka. Baudrillard mengistilahkan kondisi yang demikian dengan istilah Hiperealitas (Hyper-reality) sebuah realitas semu (Piliang, 1999a, p. 225) 
- pencampuradukkan realitas dan kesemuan imajiner dalam satu operasional yang sama - (Callinicos, 2008). Hiperealitas adalah sebuah efek yang dihasilkan dari model simulasi. Istilah simulasi digunakan oleh Baudrillard erat kaitannya dengan hubunganhubungan produksi, komunikasi dan konsumsi masyarakat, yang bercirikan overproduksi, over-komunikasi, dan over-konsumsi (Dalam Piliang, 1999). Iklan Bodrex diatas tak terlepas dari upaya untuk membangun kondisi hiperealitas, sebuah kondisi seolah benar-benar terjadi ini dalam rangka penciptaan kebutuhan baru yang dibuatbuat untuk meyakinkan calon konsumen agar membeli produk tersebut.

Sangat terlihat bagaimana iklan Bodrex diatas turut merayakan ekstasi Dromologi melalui pesan-pesan kecepatan, kata-kata “...cepat minum Bodrex!" merupakan suatu bujukan yang mengkondisikan bahwa kondisi saat sakit kepala adalah kondisi yang sangat darurat sehingga secepat mungkin harus diatasi. Kata-kata tersebut menciptakan suatu kepanikan, yang menurut Piliang (2004, p. 316) merupakan suatu perasaan ketakutan dan kecemasan yang datang tiba-tiba yang tidak dapat dikendalikan. Kepanikan ini lebih lanjut akan menciptakan suatu kondisi kecemasan yang menurut Freud (dalam Piliang, 1999) merupakan ketakutan yang tak terkendali terhadap sesuatu yang buruk mengancam.

Iklan Bodrex di atas menggambarkan kondisi masyarakat yang berada dalam ketergesaan. Sebuah kondisi masyarakat yang disebut dengan istilah dromokrasi, yaitu masyarakat yang mengagung-agungkan kecepatan. Keseketikaan ditawarkan oleh iklan tersebut, ketika aktor sakit kepala meminum Bodrex seketika itu pula sakit kepala hilang. Bodrex sebagai wujud keinstanan dalam gaya hidup manusia modern. Manusia modern tidak lagi memiliki waktu hanya untuk sekedar menderita sakit kepala yang dapat merusak rencana kegiatan kesehariannya. Sakit kepala menjadi permasalahan remeh-temeh yang dapat diselesaikan dengan obat Bodrex. Obat Bodrex digambarkan sesuatu yang harus diminum ketika sakit kepala datang, sakit kepala bukan lagi halangan serius untuk beraktivitas, jika sakit kepala cepat minumlah Bodrex. Hal ini 
disertai dengan penjelasan Bodrex mengandung 'Smart Formula', 'Triple Active Formula' yaitu formula ajaib untuk pereda sakit kepala yang menjadi bujukan maut untuk memastikan Bodrex adalah obat sakti untuk menghilangkan sakit kepala seketika.

Kecemasan-kecemasan yang dialami oleh manusia modern seperti yang terjadi pada iklan Bodrex tersebut dieksploitasi oleh iklan Bodrex dengan cara-cara yang halus dan tidak terasa. Menurut Bourdieu (dalam Fashri, 2014) dalam rangka melanggengkan dominasi yang tersembunyi tersebut, kekuasaan simbolik diraih dengan cara-cara yang halus agar tidak dikenali sehingga praktik ini menyebabkan mereka yang didominasi tidak sadar bahkan menyerahkan dirinya untuk masuk dalam lingkaran kekuasaan dominasi tersebut. Bentuk-bentuk dominasi secara halus inilah yang disebut oleh Bourdieu sebagai kekerasan simbolik yang tak kasat mata dan lembut (Gentle Violence) tak terasa. Dalam teorinya Bourdieu, selain dengan mengaburkan realitas (eufimisasi) dimana membuat kekerasan simbolik tidak kelihatan dan berlangsung lembut sehingga kita calon konsumen didorong untuk menerima pesan tersebut apa adanya, langkah selain itu adalah dengan melakukan mekanisme sensor (censorship). Mekanisme sensor ini dilakukan dengan cara menentukan pesanpesan yang boleh disampaikan dan menyingkirkan yang lainnya dalam rangka pelestarian nilai-nilai utama.

Kecepatan yang dipacu lebih cepat dari sebelumnya, akan menyebabkan manusia kehilangan kontrol terhadap kecepatan tersebut. Virilio (dalam Piliang, 2004, p. 319) memetaforakan kondisi diatas dengan istilah epilepsi, dimana kondisi epilepsi menyebabkan syaraf tidak terkondinasi dengan baik dan manusia kehilangan kontrol atas tubuhnya sehingga menyebabkan suatu kondisi ketidaksadaran. Dalam iklan Bodrex di atas, ekstasi akan kecepatan yang dimanifestasikan dengan keinstanan membuat konsumen berada dalam kondisi ketidaksadaran. J. N. Blau (1982) mengemukakan, sakit kepala ringan merupakan gejala gangguan sistem fisiologi tubuh 
pada kepala yang merupakan tanda tubuh telah mencapai batas. Blau menuturkan dalam penelitiannya, mengistirahatkan tubuh dengan cara tidur memiliki fungsi restoratif yang dapat membantu menghilangkan gejala-gejala tersebut.

Konsumen tidak sadar, menafikkan kebutuhan tubuh manusia untuk sejenak beristirahat/beregenerasi ketika dalam keadaan penyembuhan, menafikan pula efek samping bagaimana ketika Bodrex dikonsumsi terus menerus ketika merasakan sakit kepala saat sedang beraktivitas, dan bagaimana efeknya ketika sakit kepala berkembang karena pengobatan berlebihan, pasien tidak dapat sembuh tanpa menghentikan obatnya. Realitas ini disensor oleh iklan Bodrex dalam rangka perayaan budaya instan masyarakat dromokrasi.

\section{KESIMPULAN}

Iklan Bodrex di atas menggambarkan bagaimana ketakutan dan kecemasan masyarakat modern (dromotariat) terhadap kondisi sakit kepala yang datang secara tiba-tiba. Manusia modern tidak memiliki waktu untuk menghadapi hambatan tersebut, masyarakat dromotariat yang memuja kecepatan dalam ruang hidupnya mengesampingkan hal-hal yang dianggap tidak perlu, remeh-temeh, membuang waktu, tidak sesuai keinginannya. Dalam kasus iklan Bodrex ini, sakit kepala yang muncul secara tiba-tiba dianggap sebagai hambatan yang harus diminimalkan dengan segera, dan Bodrex memberi solusi bagaimana cara meminimalkan hambatan tersebut secara instan.

Masyarakat yang mendambakan efisiensi, dicerminkan oleh kegemaran mereka terhadap produk-produk instan yang akan menghemat waktunya dalam beraktivitas. Masyarakat yang demikian hanya melihat tujuan akhir tanpa menghargai suatu proses instan agar manusia dapat mengesampingkan kegiatan-kegiatan yang membuang waktu dan menggantinya dengan kegiatan lain yang dianggap berguna. Di sisi lain, terdapat resiko-resiko dikesampingkan, yang mungkin di kemudian hari dapat menjadi 
masalah baru. Semakin tinggi kecepatan yang ditempuh, semakin besar pula resiko yang mengikutinya.

\section{DAFTAR PUSTAKA}

Adelia, D., Donatella, R., Irwansyah, 2018. Efektivitas iklan youtube traveloka terhadap Keputusan pembelian (studi epic model pada iklan youtube "saat memesan tiket pesawat tak lagi Ribet" pada karyawan di jakarta). Desain Komunikasi Visual, Manajemen Desain dan Periklanan (Demandia) 03, 77-96. https://doi.org/10.25124/demandia.v3i1.1212

Anderson, T., 1986. A Comparative of Art Criticism As Propounded by John Dewey and Edmund Burke Feldman. Visual Art Research 12, 52-58.

Barthes, R., 2017. elemen-elemen semiologi. Jalasutra, Yogyakarta.

Baudrillard, J., 2015. Masyarakat Konsumsi. Kreasi Wacana, Yogyakarta.

Baudrillard, J., 2006. Ekstasi Komunikasi. Kreasi Wacana, Yogyakarta.

Blau, J.N., 1982. Resolution of migraine attacks: sleep and the recovery phase. Journal of Neurology, Neurosurgery, and Psychiatry.

Callinicos, A., 2008. Menolak Posmodernisme. Jalasutra, Yogyakarta.

Danesi, M., 2002. Understanding Media Semiotics. Arnold, New York.

Fashri, F., 2014. Pierre Bourdieu: Menyingkap Kuasa Simbol. Jalasutra, Yogyakarta.

Foster, B., Hermawan, W., Rahmayanti, R., 2019. Empowerment of Local Brand Awareness Through Packaging Uniqueness and Its Impact on Purchasing Interest. Demandia 04, 16.

Nurusholih, S., 2019. Analisis Retorika Visual Konten Iklan Produk Pada Account Instagram Bank BNI. Demandia 04, 199-214.

Piliang, Y., 2004. Dunia Yang Berlari: Mencari Tuhan-Tuhan Digital. Grasindo, Jakarta.

Piliang, Y., 2003. Hipersemiotika: Tafsir Cultural Studies Atas Matinya Makna. Jalasutra, Yogyakarta.

Piliang, Y., 1999a. Hiper-realitas Kebudayaan. LKiS, Yogyakarta.

Piliang, Y., 1999b. Sebuah Dunia Yang Dilipat. Jalasutra, Yogyakarta.

Sumartono, 2017. Metode Penelitian Kualitatif Senirupa dan Desain. Universitas Trisakti, Jakarta.

Thwaites, T., Davis, L., Mules, W., 2011. Introducing Cultural and Media Studies: Sebuah Pendekatan Semiotik. Jalasutra, Yogyakarta.

Tinarbuko, S., 2009. Semiotika Komunikasi Visual. Jalasutra, Yogyakarta.

Virilio, P., 2007. Speed and Politics. Semiotext(e), New York.

Williamson, J., 2007. Decoding Advertisements: Membedah Ideologi dan Makna Dalam Periklanan. Jalasutra, Yogyakarta.

Wulandari, D., 2016. Agar Brand Heritage Bodrex Tetap Awet Muda [WWW Document]. URL https://mix.co.id/headline/agar-brand-heritage-bodrex-tetapawet-muda (accessed 12.5.18). 
Yani, A.R., Nisa, D.A., 2018. Merancang Iklan: Implementasi DKV Dalam Komunikasi Pemasaran. Putra Media Nusantara, Surabaya. 